\title{
Stable isotope dilution analysis of orotic acid and uracil in amniotic fluid
}

\author{
Cornelis Jakobs $^{\text {a,b,* }}$, Lawrence Sweetman ${ }^{b}$, William L. Nyhan ${ }^{\text {b }}$, \\ Larry Gruenke $^{\mathrm{c}}$, J. Cymerman Craig ${ }^{\mathrm{c}}$ and Sybe K. Wadman ${ }^{\mathrm{d}}$ \\ " Department of Pediatrics, Academic Hospital of the Free University of Amsterdam, Amsterdum (The \\ Netherlands) ${ }^{b}$ Department of Pediatrics, University of California San Diego, La Jolla, CA (USA) \\ 'Department of Pharmaceutical Chemistry, University of California San Francisco, San Francisco, CA \\ (USA) and ' University Children's Hospital 'Het Wilhelmina Kinderziekenhuis', Utrecht (The Netherlands)
}

(Received June 14th, 1984; revision July 3rd, 1984)

Key words: Stable isotope dilution; Orotic acid; Uracil; Amniotic fluid; Prenatal diagnosis; Urea cycle disorders

\section{Summary}

Rapid, sensitive and accurate stable isotope dilution assays were developed for the measurement of orotic acid and uracil in amniotic fluid. The method utilizes [ ${ }^{15} \mathrm{~N}_{2}$ ]orotic acid and [ ${ }^{15} \mathrm{~N}_{2}$ ]uracil as internal standards, isolation by liquid partition chromatography and quantitation by chemical ionization selected ion monitoring gas chromatography-mass spectrometry. Orotic acid at a concentration of $0.26 \pm 0.05$ $\mu \mathrm{mol} / 1$ and uracil at a concentration of $0.55 \pm 0.13 \mu \mathrm{mol} / 1$ were detectable in normal amniotic fluid. As affected fetuses with argininosuccinate synthetase or ornithine carbamoyl transferase deficiency showed no significant elevation of orotic acid and/or uracil in their surrounding amniotic fluids, this method unfortunately seemed not to be useful for prenatal diagnosis of these inherited disorders. Nevertheless, it provides significant advantage over available methods for the quantitation of orotic acid and uracil in which the analysis of these compounds must be very accurate, highly specific and sensitive (e.g. detection of heterozygosity for ornithine carbamoyl transferase deficiency).

\section{Introduction}

Inherited deficiencies of enzymes of the urea cycle are an important cause of hyperammonemia in infancy. These may be life threatening when hyperammonemia

\footnotetext{
* To whom requests for reprints should be addressed at: Department of Pediatrics, Free University of Amsterdam, de Boelelaan 1117, 1007 MB Amsterdam, The Netherlands.
} 
presents an onset with vomiting or anorexia and somnolence which is often followed by rapid progression to convulsions, lethargy and coma followed by apnea and death [1]. Therefore, there is considerable interest in the possibility of prenatal diagnosis for parents at risk of having an affected child.

Rapid prenatal diagnosis may be obtained when it is possible to detect elevated levels of a metabolite in the supernatant amniotic fluid. Elevated concentrations of argininosuccinate have been found in the amniotic fluid of argininosuccinate lyase deficient fetuses $[2,3]$. Similarly, citrulline was elevated in the amniotic fluid of an argininosuccinate synthetase deficient fetus [4].

The possibility of prenatal diagnosis for ornithine carbamoyl transferase deficiency (OCT-deficiency) has appeared remote. Only recently has fetal liver biopsy been used for this purpose [5]. OCT is a mitochondrial enzyme, active in the liver, but it is not expressed in cultured fibroblasts or amniocytes. Further, there is no pattern of elevated concentrations of specific amino acids to look for in supernatant amniotic fluid. On the other hand, the excretion of orotic acid in urine is markedly increased in OCT-deficiency [6]. This is also true in citrullinemia and argininemia and there may be moderately elevated excretion in argininosuccinic aciduria [6]. Orotic acid is not elevated in carbamoylphosphate synthetase (CPS) deficiency.

In patients with disorders of the urea cycle and elevated orotic acid in urine, increased amounts of uracil are also excreted in the urine. In the search for a method for the rapid prenatal diagnosis of OCT-deficiency, we have devised a stable isotope dilution method using $\left[{ }^{15} \mathrm{~N}_{2}\right]$ orotic acid and $\left[{ }^{15} \mathrm{~N}_{2}\right]$ uracil. The stable isotope containing analogues serve two functions: (1) as carriers through all stages of the analytical procedure for the extremely low amounts of naturally occurring compound present in amniotic fluid and (2) they serve as internal standards for quantitation. The compounds were initially separated from amniotic fluid using liquid partition chromatography (LPC) and then quantified using chemical ionization (CI) gas chromatography-mass spectrometry (GC-MS) in the selected ion monitoring (SIM) mode. The method has the advantages of selectivity and high sensitivity.

\section{Materials and methods}

Normal amniotic fluid samples were obtained between 16 and 18 wk of pregnancy by amniocentesis and stored at $-20^{\circ} \mathrm{C}$. Amniotic fluids from pregnancies at risk were sent as sterile fluids or frozen from the centers from which they were obtained. In all of the pregnancies the status of the product was known.

$\left[{ }^{15} \mathrm{~N}_{2}\right]$ Orotic acid, isotopic purity $99.8 \%$ and chemical purity $100 \%$ was synthesized as will be described elsewhere. $\left[{ }^{15} \mathrm{~N}_{2}\right]$ Uracil, isotopic purity $97.5 \%$, chemical purity 100\%, was purchased from MSD Isotopes, Pointe-Claire, Dorval, Quebec, Canada. One hundred mesh silicic acid for LPC was obtained from Mallinkrodt (Cat. No 2847 suitable for chromatographic analysis by the methods of Ramsay and Patterson), Paris, KY, USA. Before use, the silicic acid was dried overnight at $120^{\circ} \mathrm{C}$. Chloroform and 2-methyl-2-butanol ( $t$-amyl alcohol) were reagent grade.

\section{LPC GC-MS procedure}

In this procedure $50 \mathrm{nmol}\left[{ }^{15} \mathrm{~N}_{2}\right.$ ]orotic acid and $20 \mathrm{nmol}$ of $\left[{ }^{15} \mathrm{~N}_{2}\right]$ uracil were 
added to 1-4 ml of amniotic fluid, lyophilized, acidified with $0.3 \mathrm{ml}$ of $\mathrm{H}_{2} \mathrm{SO}_{4}(0.25$ $\mathrm{mol} / \mathrm{l})$ and absorbed to sufficient dried silicic acid to obtain a free flowing powder. A new LPC-column $0.6 \mathrm{~cm}$ I.D. $\times 45 \mathrm{~cm}$ dried silicic acid hydrated with $\mathrm{H}_{2} \mathrm{SO}_{4}(50$ $\mathrm{ml} \mathrm{H}_{2} \mathrm{SO}_{4}(0.05 \mathrm{~mol} / 1) / 92 \mathrm{~g}$ dried 100 mesh silicic acid) was prepared for each sample and rinsed with $17 \%(\mathrm{v} / \mathrm{v})$ 2-methyl-2-butanol in chloroform. The sample was placed on top of the column and eluted with this solvent at $2.5 \mathrm{ml} / \mathrm{min}$, and 3 min fractions were collected. Fractions 9-14 containing orotic acid were pooled and dried under $\mathrm{N}_{2}$, as were fractions 15-21 containing uracil. The dry samples containing orotic acid were acidified with $1 \mathrm{ml} \mathrm{HCl}(0.1 \mathrm{~mol} / \mathrm{l})$ in methanol, transferred to a $2-\mathrm{ml}$ vial and redried. The acidification step is essential to obtain good methylation. For methylation diazomethane was generated from Diazald (Aldrich Chem. Co., Milwaukee, WI, USA) as described by Schlenk and Gellerman [7]. The orotic acid-containing sample was dissolved in $1 \mathrm{ml} \mathrm{10 \%} \mathrm{methanol} \mathrm{in} \mathrm{freshly}$ opened diethyl ether and saturated with diazomethane. After $5 \mathrm{~min}$, the excess diazomethane was removed by a stream of $\mathrm{N}_{2}$ and the sample carefully dried under $\mathrm{N}_{2}$ and dissolved finally in $0.2 \mathrm{ml}$ of methanol for injection into the GC-MS. For the trimethyl silylation (TMS) of uracil-containing samples, $100 \mu \mathrm{l}$ of Trisyl: BSTFA (1:1) (Pierce Chem. Co., Rockford, IL, USA) was added and heated for $60 \mathrm{~min}$ at $60^{\circ} \mathrm{C}$.

Calibration curves were prepared. Aqueous standard solutions containing fixed amounts of $\left[{ }^{15} \mathrm{~N}_{2}\right]$ orotic acid $(50 \mathrm{nmol})$ and $\left[{ }^{15} \mathrm{~N}_{2}\right]$ uracil $(20 \mathrm{nmol})$ and various amounts of orotic acid $(0.10-50 \mathrm{nmol})$ and uracil $(0.25-20 \mathrm{nmol})$ were prepared and carried through the entire procedure. In each instance, $5 \mu \mathrm{l}$ were injected into the GC-MS. GC-MS analyses were done using a Finnigan 4021 quadrupole instrument with the INCOS-DATA system. The GC column for the analyses of the trimethylated orotic acid was 3\% SP-2340 on 100/120 mesh Supelcoport (Supelco Inc., Bellefonte, PA, USA), $2 \mathrm{~mm}$ I.D. $\times 180 \mathrm{~cm}$, and the carrier gas was helium at 25 $\mathrm{ml} / \mathrm{min}$.

The injection temperature was $250^{\circ} \mathrm{C}$, the direct transfer line $280^{\circ} \mathrm{C}$, the ion source $220^{\circ} \mathrm{C}$ and the column $220^{\circ} \mathrm{C}$ isothermal. Ammonia $\left(\mathrm{NH}_{3}\right)$ was used as the reagent gas for $\mathrm{CI}$. The ammonia pressure in the source was $9 \mathrm{~Pa}$ and the ionizing voltage was $70 \mathrm{eV}$. In the electron impact (EI) mode the ionizing voltage was $70 \mathrm{eV}$. To perform SIM in each mode, the chosen ions were repetitively scanned with a $100-\mathrm{ms}$ dwell time at each $\mathrm{m} / \mathrm{z}$. All areas of the SIM peaks were integrated using the computer with operator selection of the baseline points. For the analysis of uracil-diTMS a $3 \%$ OV-17 on 100/120 mesh Supelcoport GC column, $2 \mathrm{~mm}$ I.D. $\times 180 \mathrm{~cm}$, was used. The column temperature was $130^{\circ} \mathrm{C}$ isothermal. All other settings were the same as for the analysis of orotic acid.

\section{Results}

\section{Determination of conditions for initial fractionation by $L P C$}

LPC was chosen because of excellent recoveries between $87-95 \%[8,9]$ and the fractionation obtained in which the compounds of interest are separated from other amniotic fluid constituents. An advantage of this method is that no prior deproteini- 
zation is needed. A typical LPC pattern is shown in Fig. 1. Monitoring the effluent at a wavelength of $280 \mathrm{~nm}$ provides for the optimal visualization of orotic acid. The peak at $30 \mathrm{~min}$ largely consisted of the internal standard $\left[{ }^{15} \mathrm{~N}_{2}\right]$ orotic acid. There is very little absorption of uracil at $280 \mathrm{~nm}$. Therefore, no uracil is seen under normal conditions in which the amount of internal standard $\left[{ }^{15} \mathrm{~N}_{2}\right]$ uracil is $20 \mathrm{nmol}$. The dotted line (Fig. 1) represents the pattern obtained when $200 \mathrm{nmol}$ of $\left[{ }^{15} \mathrm{~N}_{2}\right.$ ] uracil is added as an internal standard in order to determine its position of elution and the fractions that must be collected for uracil.

\section{Determination of conditions for GC-MS}

Methyl and trimethylsilyl derivatives of both orotic acid and uracil were prepared and studied. Very good chromatographic properties were experienced for both trimethyl and triTMS derivatives of orotic acid. The trimethyl derivative, however, was chosen because of better stability.

The diTMS derivative of uracil was clearly better than the methyl derivative in terms of reproducibility of derivative formation and chromatographic behaviour.

The mass spectra of trimethyl orotic acid and trimethyl $\left[{ }^{15} \mathrm{~N}_{2}\right.$ ]orotic acid obtained in the EI mode (Fig. 2) and ammonia CI mode (Fig. 3) show that considerable fragmentation occurs with El. There was much less fragmentation by the milder ammonia $\mathrm{Cl}$ method and thus the mass spectrum contained a high abundance of protonated molecular ion $(\mathbf{M}+1)^{+}$. SIM analysis of trimethyl orotic acid in amniotic fluid have been done in the EI mode as well as in the CI mode. For orotic acid and its internal standard the inns $m / z=198\left(\mathrm{M}^{+}\right)$and $m / z=200\left(M^{+}\right)$,

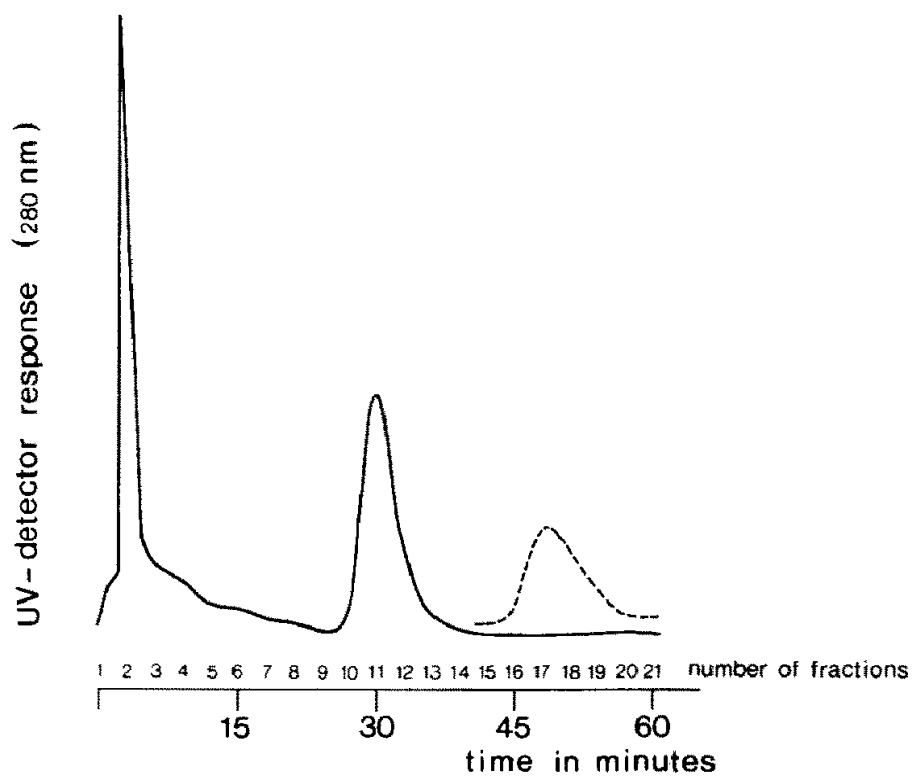

Fig. 1. LPC separation of orotic acid (peak at $30 \mathrm{~min}$ ) and uracil (dotted line). 
respectively, were measured in the EI mode, but sensitivity was unsatisfactory. Much better results were obtained in the $\mathrm{Cl}$ mode using $\mathrm{m} / \mathrm{z}=199(\mathrm{M}+1)^{+}$and $\mathrm{m} / \mathrm{z}=201(\mathrm{M}+1)^{+}$as the ions monitored. The mass spectra of uracil-diTMS and ${ }^{15} \mathrm{~N}_{2}$-uracil-diTMS obtained in the EI mode (Fig. 4) show considerable fragmentation, with the base peak at $(M-15)^{+}$. There was little fragmentation in the ammonia $\mathrm{Cl}$ mode (Fig. 5) and the major peaks were the protonated molecular ions at $(M+1)^{+}$. SIM analysis of uracil and its ${ }^{15} \mathrm{~N}_{2}$-analogue in amniotic fluid by $\mathrm{EI}$ in which $\mathrm{m} / \mathrm{z}=241(\mathrm{M}-15)^{+}$and $\mathrm{m} / \mathrm{z}=243(\mathrm{M}-15)^{+}$were measured, and by $\mathrm{CI}$ in which $\mathrm{m} / \mathrm{z}=257(\mathrm{M}+1)^{+}$and $\mathrm{m} / \mathrm{z}=259(\mathrm{M}+1)^{+}$were measured, were both satisfactory. Therefore, EI was employed for the analysis of uracil in most experiments. This has technical advantages in avoiding contamination of the ion source and pump-oil by the corrosive ammonia reagent gas. Figure 6 shows typical ammonia CI SIM chromatograms for trimethyl orotic acid $(\mathrm{m} / \mathrm{z}=199)$ and trimethyl $\left[{ }^{15} \mathrm{~N}_{2}\right]$ orotic acid $(\mathrm{m} / \mathrm{z}=201)$ from the analysis of an amniotic fluid.
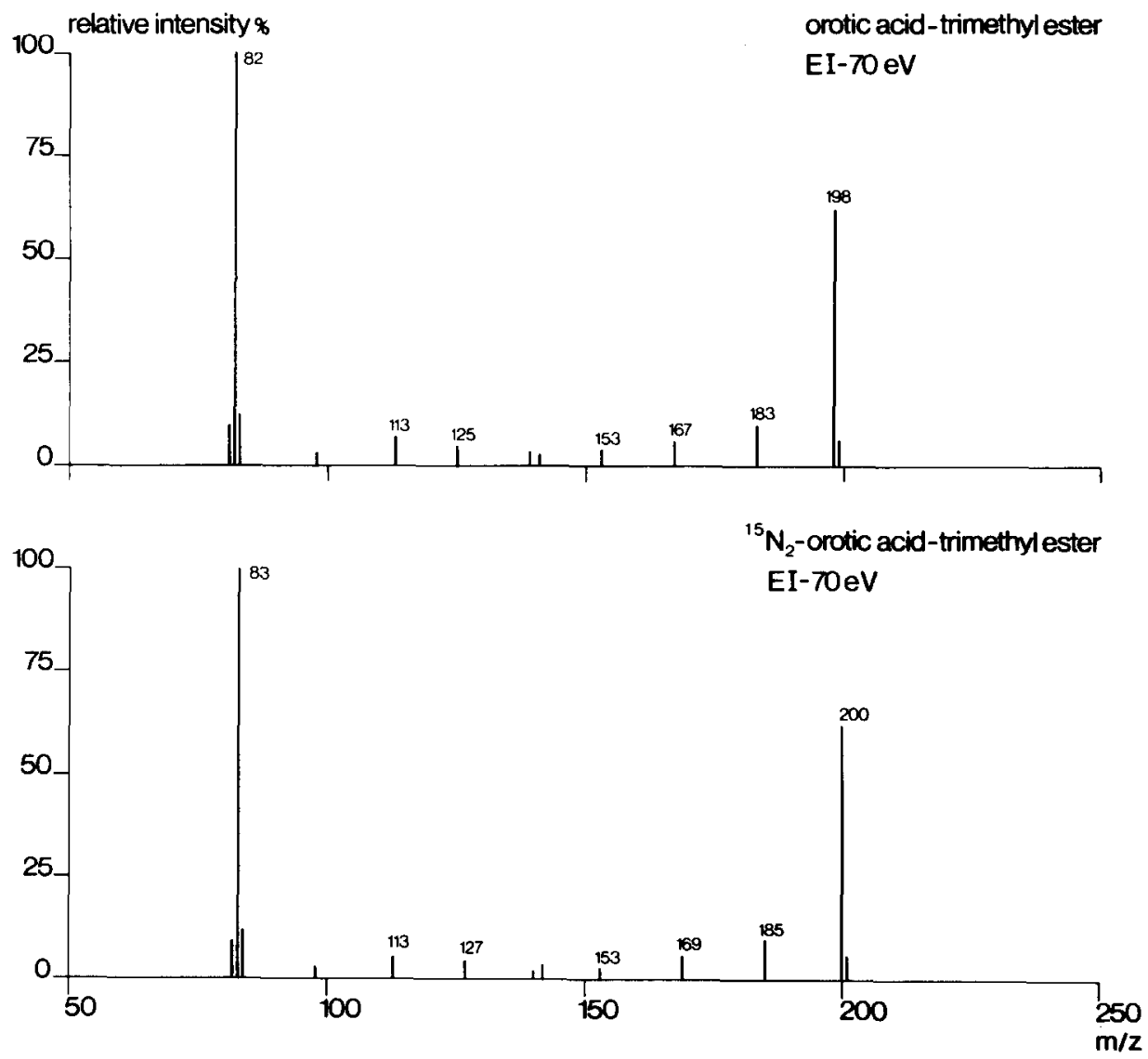

Fig. 2. Electron impact ionization mass spectra of trimethyl orotic acid (above) and trimethyl $\left[{ }^{15} \mathrm{~N}_{2}\right]$ orotic acid (below). 
Methylation with diazomethane of orotic acid that had been acidified with $\mathrm{HCl}$ gave two different trimethyl derivatives with $90 \%$ being the isomer with a higher retention time (Fig. 6). Both isomers are methyl esters, and presumably one is a dimethoxy derivative and the other a methoxy, $\mathrm{N}$-methyl derivative. The mass spectra in Figs. 2 and 3 correspond to the major isomer. Both trimethyl isomers had identical isotope ratios, and the more abundant isomer was used for quantitation. The yield of trimethyl orotic acid and the proportion of the isomers were variable if the orotic acid was not acidified before methylation. Figure 7 illustrates typical EI SIM chromatograms for uracil-diTMS $(\mathrm{m} / \mathrm{z}=241)$ and $\left[{ }^{15} \mathrm{~N}_{2}\right]$ uracil-diTMS $(\mathrm{m} / \mathrm{z}$ $=243$ ) from the analysis of amniotic fluid. Uracil-diTMS eluted at $4.6 \mathrm{~min}$. The small peak at 4 min was not a uracil derivative.

Determination of the calibration curves and the concentrations of orotic acid and uracil in amniotic fluid

The peak areas of the monitored ions for the natural compounds and their
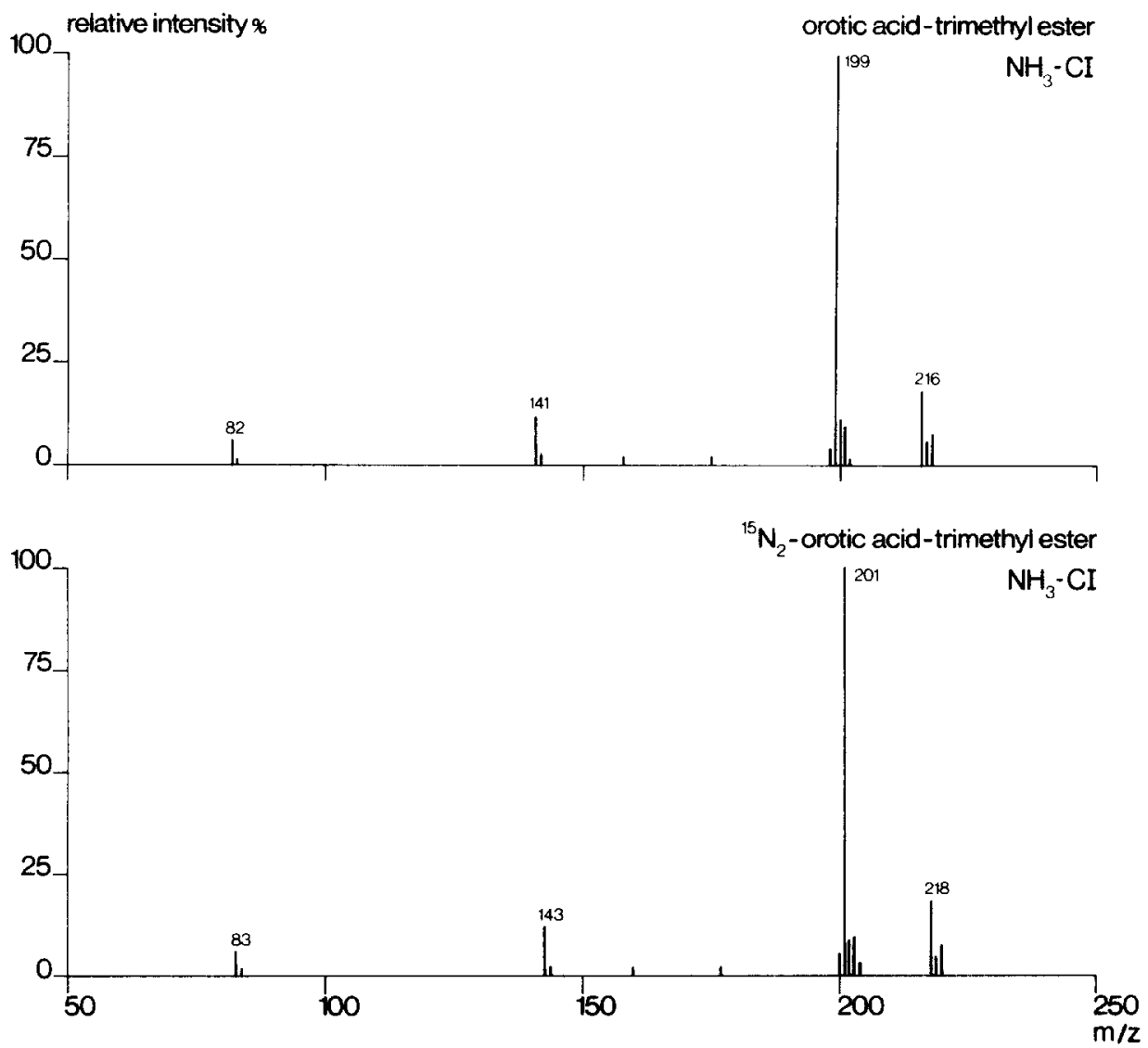

Fig. 3. Ammonia chemical ionization mass spectra of trimethyl orotic acid (above) and trimethyl $\left[{ }^{15} \mathrm{~N}_{2}\right.$ ]orotic acid (below). 

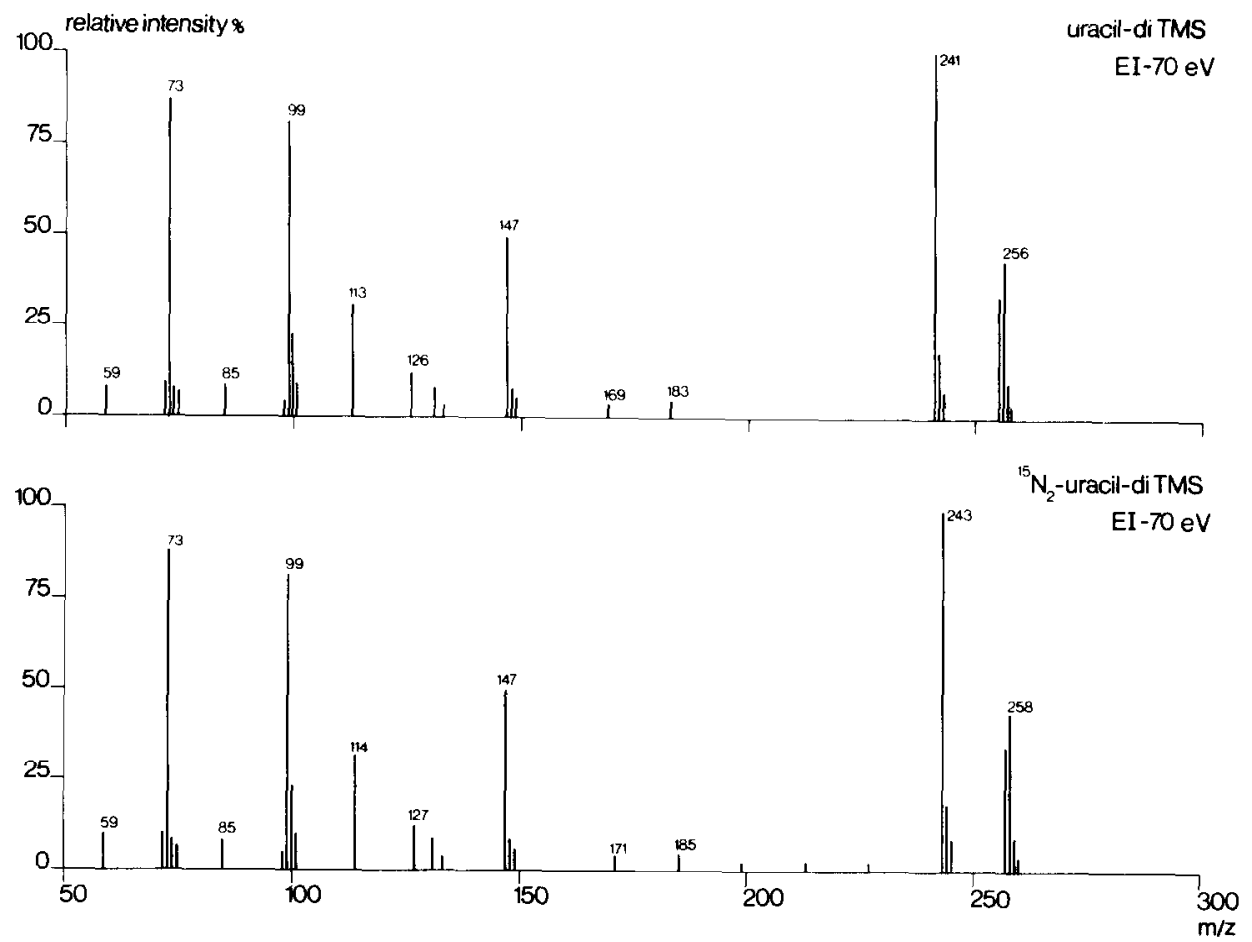

Fig. 4. Electron impact ionization mass spectra of uracil-diTMS (above) and $\left[{ }^{15} \mathrm{~N}_{2}\right]$ uracil-diTMS (below).
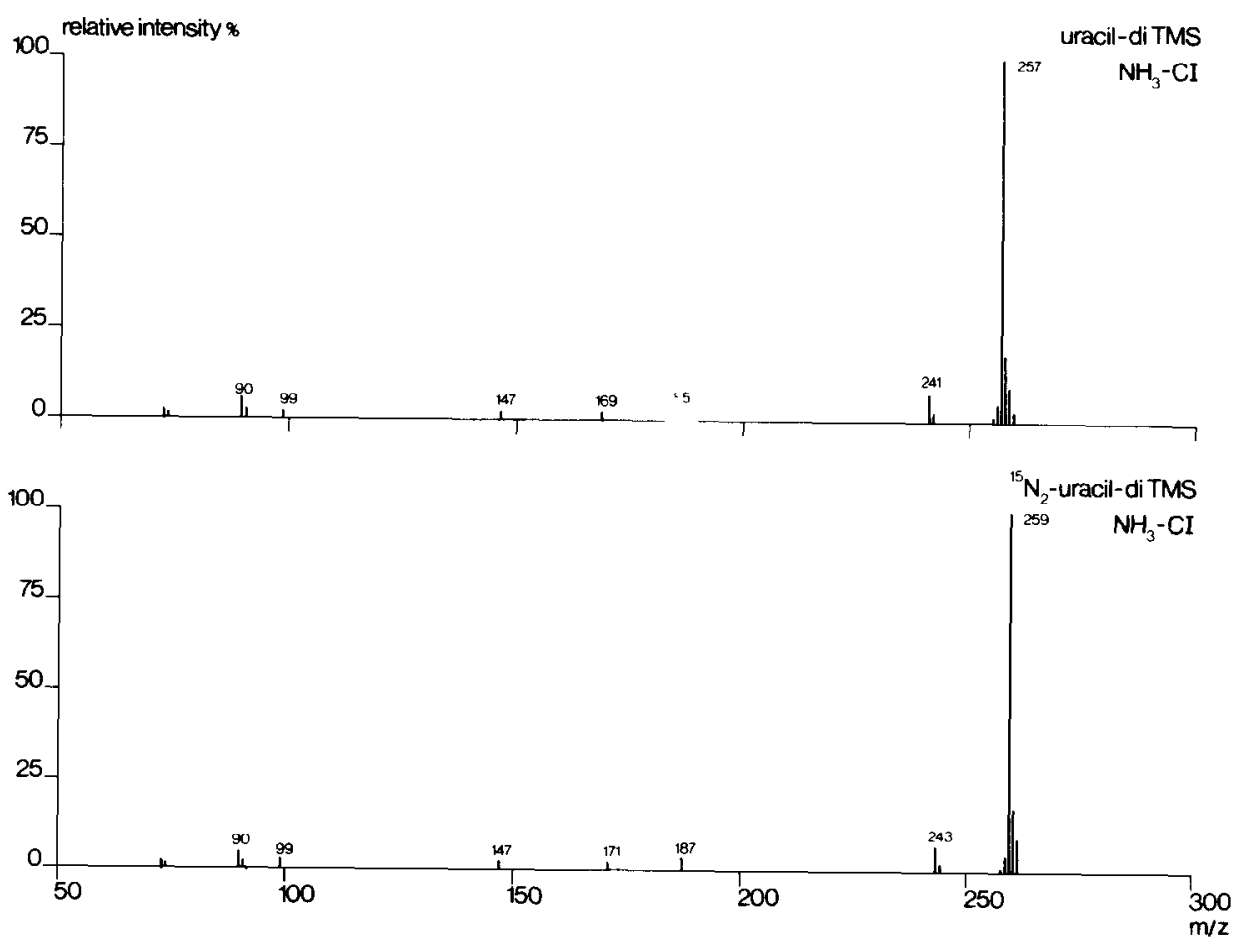

Fig. 5. Ammonia chemical ionization mass spectra of uracil-diTMS (above) and $\left[{ }^{15} \mathrm{~N}_{2}\right]$ uracil-diTMS (below). 


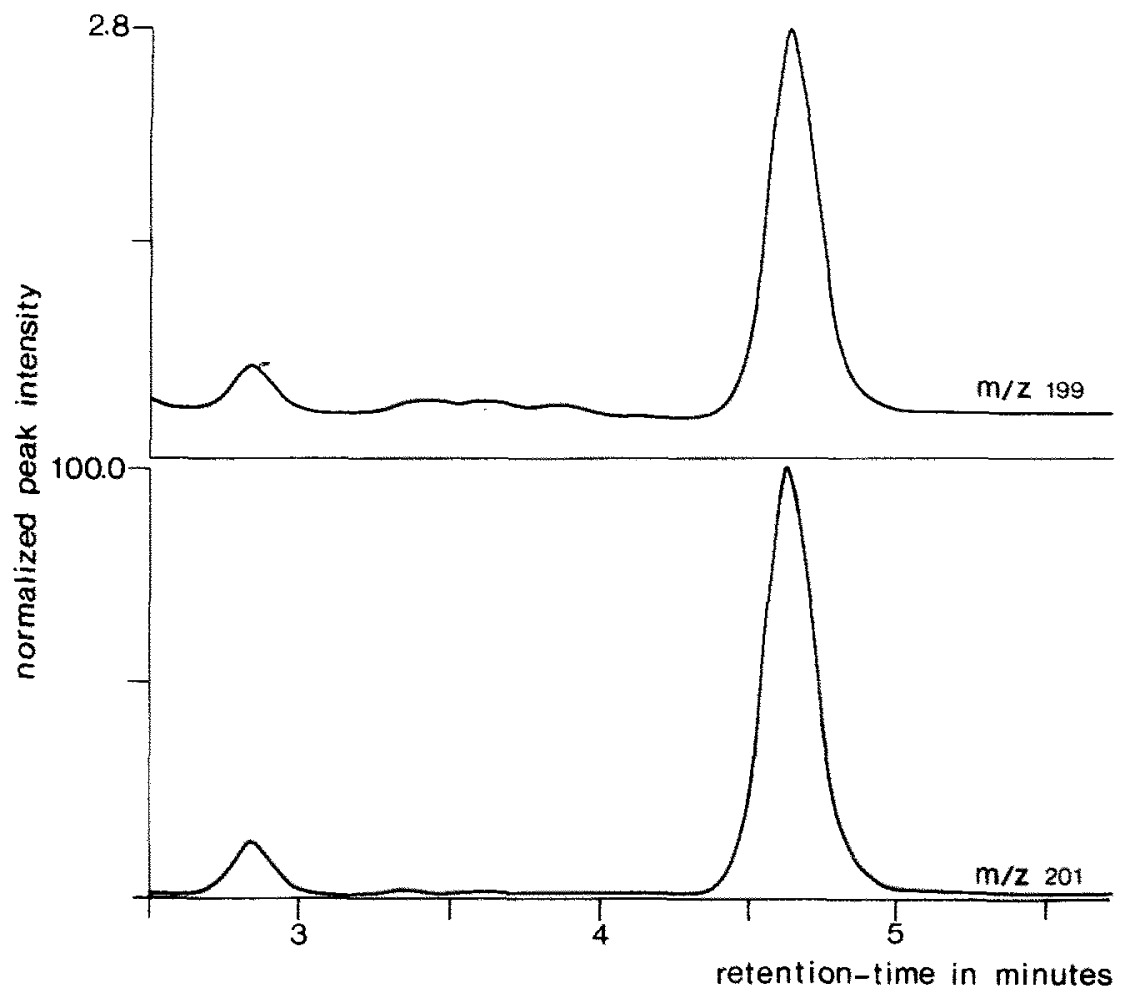

Fig. 6. Ammonia chemical ionization selected ion monitoring chromatograms of trimethyl orotic acid (m/z 199, above) and trimethyl [ ${ }^{15} \mathrm{~N}_{2}$ ]orotic acid $(\mathrm{m} / \mathrm{z} 201$, below) from $4 \mathrm{ml}$ of normal amniotic fluid.

\section{TABLE I}

Concentrations of orotic acid and uracil in amniotic fluid from control and at risk pregnancies

\begin{tabular}{llll}
\hline Subjects & $\begin{array}{l}\text { Gestational age } \\
\text { (wk) }\end{array}$ & \multicolumn{2}{l}{ Concentration $(\mu \mathrm{mol} / \mathrm{l})$} \\
\cline { 4 - 4 } & $16-18$ & Orotic acid & Uracil \\
\hline Controls $(n=17)$ & & $\bar{x}=0.26 \pm 0.05(1 \mathrm{sD})$ & $\bar{x}=0.55 \pm 0.13(1 \mathrm{sD})$ \\
& & & \\
& & & \\
& & & \\
Pregnange $=0.19-0.37$ & $0.33-0.84$ \\
citrullinemia (not affected) & 17 & 0.24 & 0.61 \\
citrullinemia (not affected) & 18 & 0.29 & 0.75 \\
citrullinemia (not affected) & 17 & 0.34 & 0.73 \\
citrullinemia (affected) & 17 & 0.37 & 0.73 \\
citrullinemia (affected) & 18 & 0.31 & 0.55 \\
citrullinemia (affected) & 20 & 0.33 & 0.37 \\
citrullinemia (affected) & 17 & 0.44 & 0.57 \\
OCT (not affected, male) & 16 & 0.34 & 1.06 \\
OCT (heterozygote female) & 17 & 0.40 & 0.87 \\
OCT (affectal male) & 18 & 0.44 & 0.98 \\
OCT (affected male) & 18 & 0.36 & 1.10 \\
OCT (affected male) & 18 & 0.30 & 0.74 \\
OCT (affected male) & 18 & & 1.21 \\
\hline
\end{tabular}


$\left[{ }^{15} \mathrm{~N}_{2}\right.$ ]analogues were determined, and the ratios of the areas of the corresponding ion pairs were plotted as a function of the ratio of the amounts of the compound and its stable isotope analogue in the sample. In each case, a linear relationship was obtained with the correlation coefficients $>0.999$. Linear regression analyses were used to calculate the concentrations of orotic acid and uracil in amniotic fluid samples.

The concentrations of orotic acid and uracil in 17 control amniotic fluids and in amniotic fluids from 13 women at risk of having an affected fetus are shown in Table I.

\section{Discussion}

Quantitative data have not previously been available on the concentrations of orotic acid and uracil in amniotic fluid [1]. The data obtained indicate that both orotic acid and uracil are normal constituents in amniotic fluid. The concentrations are so low that the stable isotope dilution methodology was important in providing the sensitivity required for the accurate measurement of the low concentrations present. It is not clear from where these pyrimidine components of amniotic fluid come, but it is likely that they are products of fetal metabolism excreted in fetal urine.

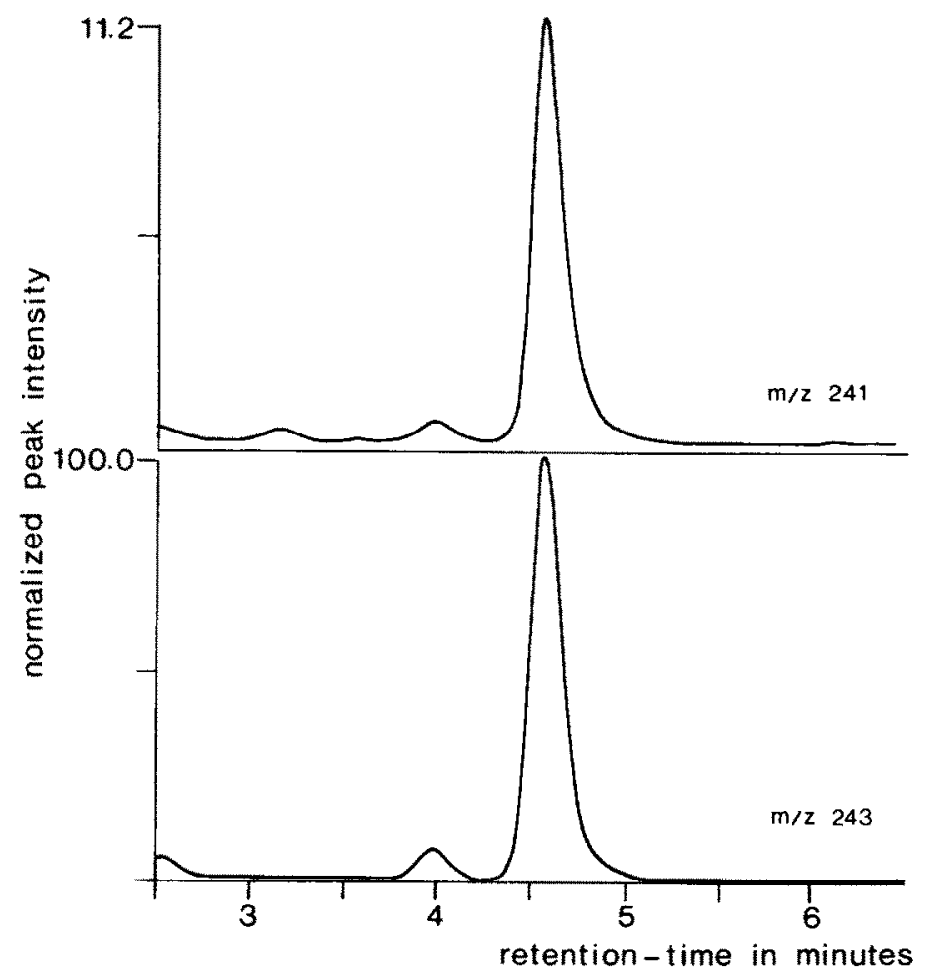

Fig. 7. Electron impact ionization selected ion monitoring chromatograms of uracil-diTMS $(\mathrm{m} / \mathrm{z} 241$, above) and $\left[{ }^{15} \mathrm{~N}_{2}\right.$ luracil-diTMS (m/2 243 , below) from $4 \mathrm{ml}$ of normal amniotic fluid. 
Enzymes of the urea cycle are active in the fetus [10,11]. Even as early in gestation as 12-17 wk the activities of the urea cycle enzymes were at least $30 \%$ of the activity of the enzyme in childhood [12]. In OCT-deficiency the utilization of carbamoylphosphate is reduced. This leads to an overflow into the pyrimidine pathway and to accumulation of orotic acid and uracil. In this X-linked dominant disorder, hemizygous males display a very markedly elevated excretion of orotic acid in the urine. In heterozygous females who have varying amounts of hepatic enzyme activity the urinary excretion of orotic acid is generally less than in hemizygous males. Asymptomatic carrier mothers of patients with OCT-deficiency may excrete slightly increased amounts of orotic acid [6]. In undertaking this study it appeared reasonable to suppose that in the presence of a fetus with OCT-deficiency, that accumulated carbamoylphosphate being produced by the fetal liver CPS which would not be utilized by the defective OCT enzyme, would lead to elevated concentrations of orotic acid and uracil in the amniotic fluid.

We had the opportunity to study the amniotic fluid surrounding 4 male fetuses known to be affected. In only 2 cases, out of the 4 , was the orotic acid concentration outside the control range, in only 1 was the concentration value $(0.44 \mu \mathrm{mol} / 1)$ more than 3 SD above the control mean. A level of $>3$ SD is generally accepted for reliable prenatal diagnosis. For uracil, in only 3 out of the 4 cases, was its concentration outside the control range. Furthermore, the unaffected normal male at risk for OCT-deficiency had also shown concentrations of orotic acid and uracil outside the control ranges. From this we have the impression that, if increased concentrations of orotic acid and uracil are found, this does not reflect fetal production only, but in part may reflect the carrier status of the mother; the magnitude of the elevation being dependent on the residual enzyme activity and protein intake of the heterozygous mother. Therefore, it is clear that prenatal diagnosis of OCT-deficiency cannot be made using this approach. The same conclusion is true for citrullinemia. From this experience it is also likely that normal concentrations of orotic acid and uracil are also characteristic of the amniotic fluid of fetuses affected with argininosuccinic aciduria. The status of the fetus with argininemia could be different and should be submitted to study.

The method developed for the measurement of orotic acid and uracil is highly specific, sensitive and accurate. It is unfortunately not useful for the prenatal diagnosis of inherited disorders of the urea cycle. Nevertheless, it provides significant advantages over available methods for the quantitation of orotic acid and uracil in situations in which the analysis of these compounds must be very accurate, highly specific and sensitive. It may prove useful in the monitoring of levels of orotic acid and uracil in the blood or urine of patients being treated for OCT-deficiency, or possibly in patients with citrullinemia or argininemia. It is especially likely that the method will prove useful for the detection of heterozygosity for OCT-deficiency following a load of protein or alanine, and we have already begun to explore this use [13]. Furthermore it seems probable that the method will be useful in the prenatal diagnosis of hereditary orotic aciduria, which represents a genetic disorder of pyrimidine metabolism. 


\section{Acknowledgements}

We thank Dr. O.W. Jones for providing normal amniotic fluids and Drs. W. Ng, H. Cann, J.M. Saudubray, D. Webster, J. Leonard, M.S. Golbus and M. Niermeyer for providing amniotic fluids of pregnancies at risk for urea cycle disorders. Aided by U.S. Public Health Service Grants No. HD 04608 from the National Institute of Child Health and Human Development, and GM 27583 and GM 17702 from the National Institute of General Medical Sciences, National Institutes of Health, Bethesda, MD, USA. Support from the March of Dimes is also acknowledged.

\section{References}

1 Walser M. Urea cycle disorders and other hereditary hyperammonemic syndromes. In: Stanbury JB, Wijngaarden JB, Fredrickson DS, Goldstein JL, Brown MS, eds. The metabolic basis of inherited disease. New York: McGraw-Hill, 1983: 402-438.

2 Goodman SI, Mace JW, Turner B, Garrett WJ. Antenatal diagnosis of argininosuccinic aciduria. Clin Genet 1973; 4: 236-240.

3 Fleisher LD, Rassin DK, Desnick RJ, ct al. Argininosuccinic aciduria: prenatal studies in a family at risk. Am J Hum Genet 1979; 31: 439-445.

4 Fleisher LD, Harris CH, Mitchell DA, Nadler HL. Citrullinemia: prenatal diagnosis of an affected fetus. Am J Hum Genet 1983; 35: 85-90.

5 Rodeck CH, Patrick AD, Pembrey ME, Tzannatos C, Whitfield AE. Fetal liver biopsy for prenatal diagnosis of ornithine carbamyl transferase deficiency. Lancet 1982; II: 297-300.

6 Bachmann C, Colombo JP. Diagnostic value of orotic acid excretion in heritable disorders of the urea cycle and in hyperammonemia due to organic aciduria. Eur J Pediatr 1980; 134: 109-113.

7 Schlenk H, Gellerman JL. Esterification of fatty acids with diazomethane on a small scale. Anal Chem 1960; 32: 1412-1414.

8 Kesner L, Muntwyler E. Automatic determination of weak organic acids by liquid partition column chromatography. Anal Chem 1966; 38: 1164-1168.

9 Sweetman L. Liquid partition chromatography and gas chromatography-mass spectrometry in identification of acid metabolites of amino acids. In: Nyhan WL, ed. Heritable disorders of amino acid metabolism. New York: John Wiley, 1974: 739-751.

10 Räihä NCR, Suihkonen J. Development of urea-synthesizing enzymes in human liver. Acta Paediatr Scand 1968; 57: 121-124.

11 Colombo JP. Congenital disorders of the urea cycle and ammonia detoxication. In: Falkner F, Krechtmer N, Rossi E, eds. Monographs in paediatrics. Vol. 1. S. Karger, Basel, 1971: 28-43.

12 Oyanagi K, Nakamura K. Sogawa H. Tsukazaki H, Minami R, Nakan T. A study of urea-synthesizing enzymes in prenatal and postnatal human liver. Pediatr Res 1980; 14: 236-241.

13 Winter S, Sweetman L, Batshaw ML. Carrier detection in ornithine transcarbamylase deficiency using L-alanine loading test. Clin Res 1981; 31: 112a. 